\title{
Health and Clinical Management - From Hospital to Home Patient Care Management
}

\section{Findings from the Section on Health and Clinical Management}

\section{Kubias, Managing Editor for the IMIA Yearbook Section on Health and Clinical Management}

Service of Medical Informatics, University Hospitals of Geneva, Geneva, Switzerland

\begin{abstract}
Summary
Objectives: To summarize last year's excellent research in the field of heath and dinical management.

Method: Synopsis of the best articlesselected for the IMIA Yearbook 2008.

Results: The selection processfor this yearbook's section on 'Health and Clinical Management' results in four excellent articles

representing various topics of the field. These papers cover areas from inpatient managerial decision support to remote patient monitoring at their homes.

Condusions: Athough these articles represent only a fraction of the worldwide work in the 'Health and Clinical Management' domain, they show promising strategies for contributing to improving the management of patient care.
\end{abstract}

\section{Keywords}

Medical informatics, International Medical Informatics Association, yearbook, patient care management, technology assessment

Geissbuhler A, Kulikowski C, editors. IMIA Yearbook of Medical Informatic 2008. Methods Inf Med 2008; 47 Supp 1: 29-32

\section{Introduction}

Health and clinical management attempts to help health care providers be more efficient. As information technology and other technologies are being used more widely every day, new perspectives arise. A key challenge is to use these technologies judiciously in order to improve the quality, safety and efficiency of health and healthcare processes.

\section{Best Paper Selection}

The biomedical literature of 2007, related to health and clinical management, was searched and an international peerreview process lead to the selection of four articles. The various fields covered by the selected articles are workflow optimization [3], CPOE related alerts [7], test results communication [9] and chronic disease management [10]. These articles represent excellent research in the domain of clinical and health information management.

Optimizing resource utilization is an important topic in health management, particularly for expensive resources like operating rooms. Although the economical and statistical basis for making rational decisions in OR management are understood [1], managerial decision support systems have been mainly focused on individual OR management [2]. In [3], the authors evaluate the means by which to provide safe and efficient managerial decision support involving multiple ORs in order to achieve better global efficiency.

Last year's major issue in the health and clinical management field was related to a reported negative impact after implementing a CPOE application [4]. Nevertheless, CPOEs are widely used as they can offer important decision support functions in order to prevent adverse drug events. It has been showed that if alerts are raised too often, and particularly if they are of little clinical importance, physicians can loose faith in alerts and ignore them all $[5,6]$. Raebel et al. obtained positive results with an alternative approach [7]: their system would raise alerts only for specific drugs in specific clinical situations known to be of clinical importance and when safer alternatives were possible. Missed test results have been shown to be of importance for patient safety as they can lead to missed or delayed diagnosis or follow-up opportunities [8]. Particularly in the outpatient setting, because patients are not in a controlled environment, test result management systems can play an important role. In [9], authors evaluate patients' satisfaction about test results communication in relation to the implementation of an automated test results management system within their primary care physicians' EHR. Although patients were not more satisfied with their physicians' skills in communication, the authors found a signification increase 
in patients' satisfaction in respect to test results communication. This reflects the impact the management system had on primary care physicians' efficiency in tracking test results.

The fourth selected article[10] deals with a public health care problem: chronic disease management. Hypertension, a highly prevalent disease, is a major health care problem, particularly as most patients are not under good blood-pressure control[11]. Designing a remote patient monitoring system is challenging as such a system must meet both the patients' and the physicians' needs. The authors developed a promising solution for remote patient bloodpressure monitoring by integrating seamlessly various technologies making the system easy-to-use for a wide range of patients as well as not interrupting the physicians' workflow. During a pilot study to test the system's ability to improve blood pressure control, 33 diabetic patients, all of which had uncontrolled hypertension as inclusion criteria, were followed. Over one third of these patients achieved to have their blood-pressure under control. This study opens new perspectives for developing similar remote patient monitoring systems for other diseases.

\section{Conclusions and Outlook}

The best papers selected for the 'Health and Clinical Management' of the IMIA Yearbook of 2008 reflect the tendency of medical informatics to expand beyond the hospital setting. Although health care management support still needs to be enhanced for the inpatient setting, offering such support for the outpatient setting is a topic of growing attention.

\section{Acknowledgement}

We greatly acknowledge the support of Martina Hutter and of the reviewers in the selection process of the IMIA Yearbook.

Table 1 Best paper selection of articles for the IMIA Yearbook of Medical Informatics 2008 in the section 'Health and Clinical Management'. The articles are listed in alphabetical order of the first author's surname.

\section{Section}

Health and Clinical Management

- Dexter F, Willemsen-Dunlap A, Lee JD. Operating Room Managerial Decision-Making on the Day of Surgery With and Without Computer Recommendations and Status Display. Anesth Analg 2007;105(2):419-29.

- Logan AG, Mclssac WJ, Tisler A, Irvine MJ, Saunders A, Dunai A, Rizo CA, Feig DS, Hamill M, Trudel M, Cafazzo JA. Mobile Phone-Based Remote Patient Monitoring System for Management of Hypertension in Diabetic Patients. Am J Hypertens 2007; 20(9):942-8.

- Matheny ME, Gandhi TK, Orav EJ, Ladak-Merchant Z, Bates DW, Kuperman GJ, Poon EG. Impact of an Automated Test Result Management System on Patients' Satisfaction About Test Result Communication. Arch Intern Med 2007;167(20):2233-9.

- Raebel MA, Charles J, Dugan J, Carroll NM, Korner EJ, Brand DW, Magid DJ. Randomized Trial to Improve Prescribing Safety in Ambulatory Elderly Patients. J Am Geriatr Soc 2007;55(7):977-85.

\section{References}

1. Dexter F, Epstein RH, Traub RD, Xiao Y. Making management decisions on the day of surgery based on operating room efficiency and patient waiting times. Anesthesiology 2004;101:1444-53.

2. McIntosh C, Dexter F, Epstein RH. Impact of service-specific staffing, case scheduling, turnovers, and first-case starts on anesthesia group and operating room productivity: tutorial using data from an Australian hospital. Anesth Analg 2006;103:1499-516

3. Dexter F, Willemsen-Dunlap A, Lee JD. Operating Room Managerial Decision-Making on the Day of Surgery With and Without Computer Recommendations and Status Display. Anesth Analg 2007; 105(2): 419-29.

4. Han YY, Carcillo JA, Venkataraman ST, Clark RS, Watson RS, Nguyen TC et al. Unexpected increased mortality after implementation of a commercially sold computerized physician order entry system. Pediatrics 2005;116(6):1506-12

5. Hsieh TC, Kuperman GJ, Jaggi T, Hojnowski-Diaz P, Fiskio J, Williams DH, et al. Characteristics and Consequences of Drug Allergy Alert Overrides in a Computerized Physician Order Entry System. J Am Med Inform Assoc 2004; 11(6): 482-91.

6. Abookire SA, Teich JM, Sandige H, Paterno MD, Martin MT, Kuperman GJ, et al. Improving Allergy Alerting in a Computerized Physician Order Entry System. Proc. AMIA Symp 2000; 2-6.

7. Raebel MA, Charles J, Dugan J, Carroll NM, Korner EJ, Brand DW, et al. Randomized Trial to Improve Prescribing Safety in Ambulatory Elderly Patients. J Am Geriatr Soc 2007;55(7):977-85.

8. Poon EG, GandhiTK, Sequist TD, MurffHJ, Karson AS, Bates DW. "I Wish I Had Seen This Test Result Earlier!" Dissatisfaction With Test Result Management Systems in Primary Care. Arch Intern Med 2004;164(20):2223-8.

9. Matheny ME, Gandhi TK, Orav EJ, Ladak-Merchant Z, Bates DW, Kuperman GJ, et al. Impact of an Automated Test Result Management System on Patients' Satisfaction About Test Result Communication. Arch Intern Med 2007; 167(20): 2233-9.

10. Logan AG, McIssac WJ, Tisler A, Irvine MJ, Saunders A, Dunai A, et al. Mobile Phone-Based
Remote Patient Monitoring System for Management of Hypertension in Diabetic Patients. Am J Hypertens 2007;20(9):942-8.

11. Wolf-Maier K, Cooper RS, Kramer H, Banegas JR, Giampaoli S, Joffres MR, et al. Hypertension treatment and control in five European countries, Canada, and the United States. Hypertension 2004;43:10 -17.

\section{Correspondence to:}

Daniel Kubias

Service of Medical Informatics

University Hospitals of Geneva

R. Micheli-du-Crest 24

CH - 1211 Geneva 14, Switzerland

Tel: +41 223728697

E-mail: daniel.kubias@sim.hcuge.ch

Appendix: Content Summaries of Selected Best Papers for the IMIA Yearbook 2008, Section on Health and Clinical Management*

\section{Dexter F, Willemsen-Dunlap A, Lee JD Operating Room Managerial Decision- Making on the Day of Surgery With and Without Computer Recommendations and Status Displays}

\footnotetext{
* The complete papers can be accessed in the Yearbook's full electronic version, provided that permission has been granted by the copyright holder(s)
} 


\section{Anesth Analg 2007;105(2):419-29}

In this paper, authors analyse how to achieve the best economically-rational managerial decisions in the operating rooms (OR) when these decisions involve multiple ORs. The priorities and the order in which they should be followed as well as the statistical basis for decision-making have been studied in previous papers $[1,2]$. This paper focuses on evaluating the quality of decisions achieved with the help of status displays (no recommendation) versus with command displays (with recommendation). The study consisted of 9 scenarios derived for an operating room schedule involving 2 ORs and submitted to anaesthesiologists, OR charge nurses and turnover personal divided into 4 groups. Each group was given the paper OR schedule with/without status display and with/without command display (computer recommendation). The decisions concerned reducing the expected tardiness from scheduled start times without effect on over-utilized OR time, reducing overutilized OR time or patient safety. Some scenarios included real-time information that was unavailable to the computer system such as that the attending surgeon in an OR has been unexpectedly called in the emergency department to evaluate a patient or that an OR required longer cleaning-time than expected because the preceding patient had excessive bleeding.

The study revealed that status displays would not help in achieving better decision-making than average random decisions. On the other hand, command displays help achieving better decisions altogether although, when patient safety was not concerned, they tend to induce users into erroneous decisions when recommendations are inappropriate. When patient safety is concerned, users rely on their appreciation rather than on computer recommendations. Command displays were of particular help when increasing the work per unit time in each OR conflicted with decisions to reduce over-utilized OR time.

\section{Raebel MA, Charles J, Dugan J, Carroll NM, Korner EJ, Brand DW, Magid DJ \\ Randomized Trial to Improve Prescribing Safety in Ambulatory Elderly Patients}

\section{J Am Geriatr Soc 2007;55(7);977-85}

Patient safety in relation to drug prescribing is an important topic. In this study, the authors focus on the prescription of some potentially inappropriate drugs for elderly patients. They designed a randomized prospective intervention trial to analyse the effect of alerting pharmacists when a potentially inappropriate drug was prescribed to an elderly patient. The intervention concerned selected drugs that were potentially inappropriate for the elderly and for which a safer alternative existed. The list of drugs, indications for medication use for which the intervention should occur and the intervention guidelines were obtained through a collaboration of physicians and pharmacists in order to achieve a widely agreed consensus. Patients aged 65 or older were included in the trial and equally divided between the intervention and control groups. For the intervention group, pharmacists were alerted by the system when a potentially inappropriate drug was prescribed and could then review the prescription with the prescribing physician. A significant decrease in potentially inappropriate prescriptions for some of the target drugs was observed in the intervention group. This study shows that alerting about specific target issues with a clear guideline for alternative options can have a significant impact on physician's prescribing behaviour.

\author{
Matheny ME, Gandhi TK, OravEJ, Ladak- \\ Merchant Z, Bates DW, Kuperman GJ, Poon EG \\ Impact of an Automated Test Result \\ Management System on Patients' \\ Satisfaction About Test Result \\ Communication
}

Arch Intern Med 2007; 167(20);2233-9

Missed test results are an important issue in respect to patient safety because they can lead to delayed diagnosis or missed follow-up opportunities. In the outpatient setting, physicians usually have to keep track of pending tests themselves, which has been showed to be far from optimal. In the present study, authors have developed a test result management application and performed a prospective randomized trial to evaluate the impact of the implementation of the application into the physicians' EHR on patients' satisfaction about the communication of test results. The developed application was designed to keep track of pending test results, acknowledgement of these by the physician and whether the result was communicated to the patient. The study showed an increase in patients' satisfaction for those patients whose physician implemented the result management application. As the physicians' skills for communications were not different, patients' satisfaction regarding this issue remained unchanged, the increase in patients' satisfaction in respect to test result communication was due to a better management of test result leading to better result communication.

Logan AG, Mclsaac WJ, Tisler A, Irvine MJ, Saunders A, Dunai A, Rizo CA, Feig DS, Hamill M, Trudel M, Cafazzo JA.

Mobile Phone-Based Remote Patient Monitoring System for Management of Hypertension in Diabetic Patients

Am J Hypertens 2007;20:942-8 
Poor blood-pressure control in hypertensive patients is a major concern for public health. Many intervention trials have been carried out but were found to have little impact. In the present paper, authors present a novel approach in designing a remote patient bloodpressure monitoring system. From focus-group meetings they held with patients and physicians they found that patients were concerned about having to do as little as possible manipulations with the system and not having to use technology like PDAs or computers; physicians were concerned about their usual workflow not to be disrupted. This lead to the design of a blood-pressure (BP) monitoring system made of a Bluetooth-enabled monitoring device communicating data automatically to a pre-programmed mobile-phone that in turn transmitted the BP data to a central server. The only required intervention from patients was to take their BP. The central server, upon processing the received data, would automatically decide, if required, to send patients instructions on their mobile phone like performing more BP measures or to schedule an appointment with their physician. In the case the central server would detect critical BP values, it would alert the corresponding patient's physician. Using an interactive telephone system, patients, physicians or their assistants could initiate a request for a fax report of the patient's measured BP values that would be sent automatically to the physician's fax. Once the remote BP-monitoring system was developed, authors performed a pilot trial with 33 diabetic patients, all with uncontrolled ambulatory BP as inclusion criteria. This pilot study showed promising results: during the study, patients performed substantially more BP readings than was planned, no critical alerts had to be sent to physicians due to critically abnormal BP values (sustained high or low BP), physicians' workflow was not disrupted and patients were satisfied with the system in regard to simplicity of use. By the end of the study, one third of patients had a controlled hypertension. Although the design of the study did not permit to determine the mechanism of BP control improvement, this novel approach opens new perspectives in tele-monitoring and tele-management of other physiologic parameters such as bloodglucose. 